Amit Mitraa , Email: Amit.Mitra@uwe.ac.uk

Nicholas O'Regan', Email: Nicholas.O'regan@uwe.ac.uk

David Sarpongc, Email: David.Sarpong@brunel.ac.uk

Authors Affiliation:

a,bBristol Business School

University of the West of England

Frenchay Campus

Bristol, BS16 1QY

United Kingdom

'College of Business, Arts \& Social Sciences

Brunel Business School, Brunel University London

Kingston Lane

Uxbridge UB8 3PH

United Kingdom

\title{
Cloud resource adaptation: A resource based perspective on value creation for corporate growth
}

\begin{abstract}
Instantaneous access to firms' resources, any-time, any-where dominates contemporary discourse on business systems transformations. The advent of utility computing through cloud based resource development has therefore altered both the perception of IT resources and the expectations of their use in practice. Drawing on the resource based view as a theoretical lens; we examine the nature of unique capacity development in adapting cloud based technologies for corporate growth. Focusing on the experiences of two multinational firms that have recently implemented strategies aimed at integrating and leveraging value from cloud computing, we argue that while cloud computing may improve organizing at systems and operations levels, the development of unique competencies of skills and knowledge acquired through the implementation of cloud is what is likely to lead to the creation and capture of value relevant for competitiveness. Our case evidence suggests that as information management infrastructure gets altered, the cost savings and efficiency gains that result, may lead to sustained corporate growth and stronger external networks. We conclude with some implications for the theory and practice of value creation for corporate growth.
\end{abstract}

Keywords: cloud computing, resource based view, unique competencies, value creation,

\section{Introduction}

Instantaneous access to firms' resources, any-time, any-where, dominates contemporary discourse on business systems transformations. The advent of utility computing through cloud based resource development has therefore altered both the perception of IT resources and the expectations of their use. The need for business system transformation means interest in cloud computing has increased significantly in the past decade. As a "model for enabling ubiquitous, convenient, on-demand network access to a shared pool of configurable computing resources (e.g., networks, servers, storage, 
applications, and services) that can be rapidly provisioned and released with minimal management effort or service provider interaction" (Mell and Grance, 2011: 3), cloud computing is characterised as a fundamentally different way of invention, development, deployment, scaling, updating, and paying for information and communication services (Marston et al. 2011), and has become the driving force for corporate growth. Nevertheless, many organisations that are moving 'onto the cloud' are initially challenged by the notion of billing at point of use and subsequently by the whole changes to decision making that this sort of service orientations create (Sultan 2014). In addition, they face the challenge of developing the requisite capabilities that will enable them capture relevant value from their cloud resource investments.

A feature of new developments using cloud computing has been the re-orientations of capacity (Gupta et al., 2013). It is common to find cloud use by organisations in general and SMEs in particular to scale operations to cater to hitherto unknown levels of client requests. Expectations of sustainability and society demand drastic reductions in carbon footprints that would be infeasible to support with big data centres for organisations. In this regard, cloud implementation by large organisations could provide various pointers to bolstering of green credentials within specific industries.

In this paper, we examine how organisations reconfigure their cloud based resources to develop competitive advantages. Given that technologies are not neutral in their impact on organisations, we argue that cloud based resources by virtue of their intangible nature will require unique managerial capabilities to leverage their potential for corporate growth. Developing our contribution in the context of two multinational firms that recently implemented strategies aimed at integrating and leveraging value from cloud computing, we draw on the resource base view (RBV) as a theoretical lens to examine how unique and inimitable skills may contribute to successful implementation of cloud technology and the subsequent capture of sustainable value that drives corporate growth.

Our study makes two distinct contributions. First, it contributes to the literature on cloud based computing by demonstrating that the skills for implementing the cloud are difficult to acquire and only 
possessed by very few which makes it less likely to be mobile. Second, we delineate how unique competencies of skills and knowledge acquired through the implementation of cloud may to lead to the creation and capture of value relevant for competitiveness. The paper is organised as follows. First we present a resource based view of cloud computing and go further to delineate the nature of cloud based resource capabilities. Following this is our research methodology. Next we present our research findings and a comparative case analysis of the two case organizations. We then conclude with a discussion of our findings and some limitations of our study.

\section{The resource based view}

The resource based View (RBV) emerged as a corrective in accounting for differential performance among firms embedded in the same environment. RBV theory argues that the type of resources employed by a firm to compete is crucial for its profitability and resources can only confer sustainable competitive advantage when they are valuable, rare, inimitable, and lack substitutes (Barney, 1996; 2001; Priem and Butler, 2001; Wernerfelt, 1984).For the RBV to hold there are two critical assumptions. The first assumption is that firm resources are heterogeneous. The second more important assumption is that the resources are indeed "sticky" or immobile. While the first assumption may help to account for why firms may have different implementation capabilities for the cloud, the second, with respect to implementation capabilities is more difficult to leverage in practice in todays' business environment (Kraaijenbrink et al., 2010). We argue that while cloud implementation ability is possibly valuable $(\mathrm{V})$, it is not necessarily rare $(\mathrm{R})$ or Inimitable (I). The rate of change and evolution in the technology industry is fairly quick and there exists a strong market for individuals and organizations with skills in cloud deployment. Given that there exists such a market, the resource (competencies in cloud computing), is essentially tradable and therefore difficult to believe that such resources need not necessarily confer superior advantages (Kraaijenbrink, et al., 2010; Peteraf, 1993). From this perspective, Wade and Hulland (2004) argue that Information system (IS) resources of the firm may be accounted for through a couple of determinants that include IS assets (technology based) and IS capabilities (systems based). These IS assets have an inherent disadvantage, in that they can be 
easily copied by competitors and therefore fragile with regard to the sustainability of competitive advantage (Leonard-Barton 1992). By its nature, deployment of IT resources drives development of technical capacities among staff responsible for rolling out, as well as those who are using the new IT resource. Such emerging applied embedded IT capacity as a result of new deployments is often inimitable as it is usually distinctive to specific organisations (Ravichandran and Lertwongsatien, 2005). In this article we concede many of the criticisms pioneered by the static approach but resist abandoning the pre-existing reality of competitive advantages that inimitable capabilities could deliver to an organisation (King et al., 2001; Priem and Butler, 2001b).

Corporations are continually seeking to develop unique inimitable capacity so that they can create competitive advantage as well as remain ahead of competitors. At the same time technology implementation that would enable development of such capacity is likely to encounter resistance to change within them. Corporations that succeed in implementing change by overcoming such resistance are usually supported by leadership that has foresight, are able to handle risk at the same time become considerably unique in the way their business systems operate (Mitra and Neale, 2014). It must be noted here that instances of successful IS implementations within corporations over the last couple of decades seems to have been significantly driven by the need to address business goals. Such an orientation, as for instance in the study conducted within Nestlé by Mitra and Neale (2014), is in contrast to findings which showed that co-ordinating IS plans with business plans impedes effective IS planning (Lederer and Mendelow, 1989). Despite many successful IS implementations, instances of IS failure have lingered. Such failure has enabled the issue of alignment to be pre-eminent in the context of large corporations. Just like Mitra (2001) identified maturity to be a key parameter in Geographic Information Systems (GIS) implementation within British local government, similarly Luftman (2003) categorises alignment to be dependent on six categories of maturity.

Elsewhere, prior literature makes a case for when resources tend to possess mobility barriers. A key argument here rests on causal ambiguity- when the tacitness, complexity, and specificity in a firm's skills and resources make the source of competitiveness unknown (Mosakowski, 1997; Lippman and Rumelt, 1982). It also follows that the relationship between causal ambiguity, resources and firm 
performance is unknown (King and Zeithmal, 2001). Arguably, the creation of inimitable resources is that which drives competitiveness as it impedes the imitation. Nevertheless, it can be extremely difficult to transfer or leverage inimitable resources for potential re-use at a marginal cost, thereby constraining replication required to sustain competitiveness. In the IS context, we observe that the development of such critical resources underpinning competitiveness is driven by a number of factors. First, all discrete operations prevalent in different regions of the corporation are transformed into a single uniform system. Second, once this uniform system becomes operational it produces its own uniqueness. Whilst the first development through integration brings about a capacity to monitor enabling centralised control, and greater efficiency in use of resources (Mitra and Neale, 2014). The second development tends to affect the organisations external position with reference to competitive advantages.

\section{Cloud based resource capabilities}

Growing evidence suggest that IS capacity development leads to resource advantages. Nevertheless, maturity of using competencies can make a difference to the way organisations eventually acquire competitive advantages (cf. Bharadwaj, 2000; Mitra and Neale, 2014). For example, Mitra (2001) in his study of the implementation of geographic information systems found that different levels of maturity in IS use usually leads to competing formats through which IS capacity development evolves. Cloud computing as IS capacity, in recent times, has become an integral part of successful organizing. This refers to both the applications delivered as services over the Internet and the hardware and systems software within data centres that provide those services (Armbrust et al., 2010; Voorsluys, et al., 2011). Embedded in high velocity environments characterised by frequent disruptions of technological trajectories, the competencies required for cloud capacity development requires continuous adaptation and change which may be distinctly linked to the maturity levels of the implementing organisation. Note that the notion of introducing cloud computing is probably somewhat different in contrast to traditional systems. Owners of systems are readily aware of the resource modifications that result with the introduction of cloud computing yet the users apart from realising a rise in resource availability are unlikely to be able to discern any changes to system functionality. So the issue of creating user 
incentives that will promote alignment (Ba et al., 2001) does not apply in the strict sense within a cloud computing construct.

Bharadwaj (2000) posits that IT capability is a rent generating resource that is not easily imitated or substituted in large companies, further Armbrust et al. (2010) has clarified that pay as you go, as used in cloud computing, is clearly tied to cloud based usage. Renting usually involves paying a negotiated amount over a fixed period irrespective of use. Pay as you go involves metering usage and charging based on actual usage, independently of the period over which the usage occurs. With the advent of cloud computing, this is perhaps a key difference that has come about in the estimation of IT resources consumption. Dwelling on scale and simplicity as the new dimensions that cloud brings to the context of multinational companies, Grossman (2009) concurs, that pay as you go to use cloud capacity is a facet that has hitherto remained unknown. In the context of large organisations as operations scale to international contexts, using multiple proprietary providers could lead to challenges in application of security policy (Jaeger et al., 2008). Reductions in budgets and higher space requirements as computing becomes more web based is a compulsion that is driving large organisations to rethink their current capacity provisioning (Sarkar and Young, 2011). Cloud obviously provides a veritable option that is increasingly being taken seriously by large organisations.

Interoperability is a key challenge that many traditional multinational organisations face when they aim to migrate current systems onto cloud based resources. Dillon et al. (2010) point to the proprietary software conflicts that may come about when considering an organisation's own existing legacy systems. Outsourcing of IT operations is a slightly different type of activity that has distinct similarities with resource outsourcing to proprietary software houses. In this context, the cloud computing led integration of IT capabilities might be synonymous with outsourcing to develop integrative capability (Pollalis, 2003). From a RBV perspective, it may be posited that the greater the integration of legacy data into cloud systems, the greater would be the likelihood of developing unique capacities leading to specific non-imitable competitive advantages that an organisation could garner (Galbreath, 2005). While both SMEs as well as large organisations are likely to acquire unique competitive advantages 
through data integration yet with higher demand expectations, the need for such advantages will be greater in larger organisations. Knowledge based competitive advantage (Grant 1996a, 1996b) is probably the most complicated to distinguish from those acquired through other forms of valuable, rare, inimitable and non-substitutable resources.

The development and integration of cloud computing into large organisations may not necessarily be a random, arbitrary development. Martens and Teuteberg (2012), by juxtaposing cost projections that included, co-ordination costs, IT service costs, and maintenance costs on the one hand with a combination of three risk types that included integrity, confidentiality and availability, have shown the emergence of decision scopes that support the development of specific cloud infrastructures. As evidenced in the extant literature, it is clear from this research (Martens and Teuteberg 2012), that security and cost are dual prerogatives that drive development of information infrastructures. The implications of reduced cost is probably the most widely appreciated advantage of introducing cloud within large organisations as has been reiterated by Avram (2014) using the dimensions of 'utility' and 'guarantee'. Therefore, it may follow that managerial decision making in large organisations is reliant on information availability that may in turn be dependent on levels of cloud integration.

'Adaptive infrastructure' is the term that used by Marston et al (2011) to explore current capacities of cloud among organisations. From a demand perspective, this sort of adaptive infrastructure enables providing different interfaces to different end users, which may be an expectation of information capacities of organisations. Marston et al (2011) qualify their analysis of 'adaptive infrastructure' by positing the particular scaling potential that cloud computing provides. As scaling by virtue of software enabled resources becomes the norm, it is likely that dependence on service providers would diminish whilst at the same time innovative capacities (Lin and Chen 2012) will lead to long term gains in competitive advantages of the organisation. Using the technology-organisation-environment (TOE) framework of innovation diffusion theory Hsu et al (2014) examined 200 firms in Taiwan to reiterate that perceived benefits, business concerns, and IT capability are significant determinants of cloud computing adoption. This survey by Hsu et al (2014) on cloud computing based innovation supports the notion of a direct and positive relationship to the long term strategic advantages of an organisation. 
Undoubtedly, the central tenet of RBV theory which posits that the type of resources determines the extent of profitability and consequent competitive advantages that might ensue to an organisation has become axiomatic. Extant literature on RBV seems to have wrestled with the conceptualisations of 'causal ambiguity' that relates to tacitness, complexity, and specificity (Mosakowski, 1997; Lippman and Rumelt, 1982) in a firm's skills and resources on the one hand and properties of rarity and inimitability on the other. As both these ends of a continuum are clearly subjective, the constitution of competitive advantage based on these dimensions will be dependent on the skills and applications developed by staffs in organisations implementing cloud computing. It is therefore likely that there will be variations in the skill levels of specific organisations implementing cloud solutions that would in turn contribute to commensurate competitive advantages. The subjective nature of such competitive advantages are likely to remain an abiding unknown of RBV based evaluations and interpretations, guided primarily by the skills and abilities of staffs to utilise cloud computing resources to cater to needs of the organisation.

Given the unknowns that have lingered in the domain we developed the following research questions to drive our empirical enquiry: How does cloud led alterations of information management infrastructure of organisations lead to corporate growth? Second, to what extent does cloud integration enhance the value of resources for competitiveness?

In the next section, we outline our research methodology and introduce our case organisations.

\section{Research Methodology}

Our empirical research context was the global manufacturing sector focussing on two major organizations' with global reach. The first is a British corporation that is well known in the oil and natural gas sector and the second, a Japanese car manufacturer that has significant UK based manufacturing capacities. Our selection of these two organizations was based on the premise that they offered a particularly rich context to study a contemporary organizing resource like cloud computing in matured industries embedded in rapidly changing fast-moving market (Roland, 2004). We also 
adopted an exploratory research design and methodology, as our aim was to develop insights into the implementation of cloud computing within a real-life context where the boundaries between theory and practice are not clearly defined (Yin, 2013).

Data for our inquiry was chiefly collected through interview. We complemented this with additional data from different sources. These included archival material, company brochures, emails, and data held on Sharepoint repositories. Narrative accounts were compiled through interviews of five members of the senior management in each organisation. Of the senior management, two were managers whose roles were directly related to IS within the companies, two were involved in supply chain functions and one other manager was involved with general management. A topic guide based questionnaire was used to gather data in the two organisations. We focused on the key information challenges that were being faced by the organisations, drivers of cloud integration, strategic sectoral imperatives, cloud based information management platforms, implementation experiences with regard to major suppliers of cloud infrastructure, and competitive advantages. Prevalent non-disclosure conditions do not permit us to use either the names of the organizations or reveal the identity of staff who were interviewed for the study. For the purposes of this paper the companies will be referred to using pseudonyms as Deepwater's Rigs (DR) and Fuji Motors (FM) respectively.

We followed a four stage process of data analysis and interpretation as developed in the 'framework approach' advanced by Ritchie and Spencer (1993). Notwithstanding, some important minor modification of the process was made in response to some of the salient theoretical and methodological commitments of the study. For instance, retroduction as opposed to induction or deduction as an inferential strategy required the generation of mechanisms to help advance explanations. The stages involved in the process included Familiarisation, Identifying thematic frameworks, Mapping and Interpretation. Although presented here in a linear fashion, the stages observed in practice were processual, as mentioned iterative and again had a circular dimension.

Familiarization: 
We carefully studied and reflected upon the data that we collected in both the organizations to see whether they matched correctly with what was heard and seen during our interactions. It was also an opportunity to identify some recurrent phrases which were 'analytically converted' (Strauss, 1978: 30) into relevant themes corresponding to the research questions and these are represented in the dimensions shown in table 1 . Thus a principal aim here was to identify the key ideas on cloud integration as well as recurrent and conspicuous themes related to cloud implementation in the two case organisations. At this stage emerging insights were also noted for exploration and refinement in the next stages of the process.

Identifying thematic frameworks:

The initial themes identified from the data were first grouped under the general rubrics of Expectations, Experiences, Realities, Hopes, and Fears. These specific themes were selected following Loveridge (2009) and Cunha et al. (2004) who argue that the sort of organizational futures people often seek is generally driven by these fundamental 'primers.' This recursive process also involved an 'extensive recycling of concepts and perspectives' (Bargar and Duncan, 1982:2). At this stage, additional themes and categories were elucidated and developed into thematic frameworks which were subsequently cross referenced.

Indexing:

The identified themes and categories were indexed to generate analytical categories and themes and also explore viable theoretical explanations. Indexing here was also about making sense of the gaps between identified themes in order to develop a meaningful and robust understanding of the data to enable subsequent interpretation and verification of meanings.

Mappings and interpretation:

In mapping and interpreting of the data, causal mechanisms based on our knowledge of organizational structures and role of the respondents in the selected organizations were iteratively identified by first moving from the abstraction of cloud use. As such the process was influenced by the research objectives of adequately delineating alterations of the information management infrastructure and several themes and categories on resource valuation that happened to emerge from the data. 
Abstraction as used here refers to the cognitive process of building concepts and frameworks or what Ragin (1994) referred to as analytical frames and images grounded on the observed perceptual instances as captured and elucidated in the triangulated data. The move from this high level of abstraction to the concrete or empirical event was aimed at identifying the 'deep structures' and observed empirical patterns. The external causal and relational connections between the theoretical ideas grounded in the social theory of practice and the empirical patterns were then used to enhance and improve understanding of the nuances of the observed patterns and the pre-theoretical goals of the actors as they engaged in the implementation of cloud computing. In other words, developed concepts, which were deemed to be abstract representations, were iteratively linked back to reality and so provided immediate knowledge of the connections between the observed discursive practices and cloud integration in the technology-market linking process.

\section{DR: Moving email services to the cloud:}

A key decision parameter for $\mathrm{DR}$, was the extent to which the email services it was seeking to procure, needed to be customised to DR's specific organisational context. On the one hand the company sought to get the economic and commercial benefits associated with standardised Cloud offers but, on the other hand, recognised that that the nature and complexity of its business required significant custombuilding. As one of our respondents explained:

It became a conversation about where we wanted to get Cloud economics and Cloud commercials but actually the reality was that it always looked like more of a custom-built environment.

The above mentioned quote corroborates causal ambiguity characteristics of complexity and specificity as posited by Lippman and Rumelt (1982). Potentially the effectiveness of the fit of cloud solutions with the complexity of DR's environment would determine both extent of inimitability as well as unique value of the resource with respect to competitiveness. Following a number of detailed rounds of discussion and negotiation, the contract was eventually awarded to T Systems, the corporate customer division of Deutsche Telekom in July 2012. Under the terms of the contract T Systems were to provide a secure private cloud enabling DR's 830,000 plus employees around the world to access 
email services from a range of mobile and computer devices. The contract was for a five-year period based on a "pay-per-use" model.

\section{DR's exploration of moving their information management platform to the Cloud}

DR's exploration of this option has followed a similar path to that of email services with regard to the procurement process. It issued a request for information (RFI) to test the market and to identify potential suppliers and entered into discussion with some of the dominant players like Amazon Web Services (AWS).

These large providers of public Cloud services have presented DR with a new and rather unexpected set of challenges. Providers like AWS provide a standardised service that takes little account of the size or nature of the purchasing organisation. As one of our respondents explained:

You can forget trying to have a conversation with Amazon in the way we used to with Hewlett Packard (HP) where they (HP) will take on certain service levels and undertake to do special things for you as a customer. No chance [with Amazon]. DR as an organisation has as much firepower with Amazon as I have as an individual customer. It makes no difference whatsoever to them so you need a different set of levers to manage your risk exposure around that and that leads you actually to a different... architecture and a completely different dynamic.

This quote demonstrates the balance of power between provider and purchaser is different from that which large corporations like DR have come to expect. DR, like most other global organisations, is used to having strategic leverage with suppliers but the dynamics of public Cloud services are unusual. In a way such challenges in cloud implementation to leverage advantages confirms Kraaijenbrink et al.'s (2010) characterisation of stickiness of the eventual reconfigured resource. A few large providers dominate segments of the newly emerging Cloud industry and these first movers have been able to exploit the economies of scale and experience to bring costs down, tipping the balance of advantage in their favour.

Moves to Cloud-based provision can seem to be relatively inconsequential from the end-users perspectives but from a broader organisational perspective, they can have far-reaching and unexpected effects. Managers at DR, for instance, have found that the exploration of Cloud-based solutions has required them to rethink many of their existing practices and processes. Executives involved in the 
decision-making process report that there is a potential impact on everything from legal frameworks, through billing and charging for IT services to the way Information Systems performance is measured. Impact of such changes to the decision-making process will surely create uniqueness to IS capabilities (Wade and Hulland, 2004) of DR.

From the end-users point of view a change in the provision of email services or an information management platform can go almost unnoticed but the adoption of cloud services means that "every decision has a new complexion to it". For example with regard to legal contracts, DR's legal teams are used to negotiating specific clauses in contracts but in a "multi-tenant" environment that doesn't make sense and Amazon, requires its customers to adopt standard terms and conditions. The adoption of standard terms and conditions has knock-on implications for the way risks are managed. For instance if AWS went down, how would disaster recovery be managed in this new environment? Similarly, the fact that charges for cloud services are consumption-based means that the way IT services are billed for internally, needs to be altered to reflect this and incentives need to be in place to create economies on the "consumption" of chargeable services. As a respondent put it:

it's like a prism - take the example of how we charge for IT internally - here we have a specific way of charging the business for services which is not hour by hour/consumption based, it is pretty much year by year consumption. So you can have a situation where, by the very nature of the Cloud, you can peak, move in, and see lots of different things and your internal charging models encourage that level of use and variability but that isn't an advantage anymore, that's a problem. So it's how you begin to start to chip away at a series of financial mechanisms of governance that might have been in place for twenty years and ... there are lots of dead bodies in stuff like that. You have to work your way through (myriads of issues like this) to begin to leverage the advantage that this other thing (the Cloud) gives.

Alterations of such kind where traditional IS assets that have been valued through capital expenditure (Capex) approaches are now with the implementation of cloud being operated through operational expenditure (Opex) approaches is likely to have both cost and profit implications in a global organisation like DR. Instead of being just a cost centre, DR could potentially become a profit centre (Choudhary and Vithayathil, 2013) by providing consumption based IT capacity to its employees. As cloud implementation encourages the development of in-house profit making capacities there is likely to be additions to corporate growth over time. Similar sentiments are expressed in the following 
comments that illustrate how difficult it is to implement changes that on the surface can appear quite modest but have wide-scale implications.

When you are trying to create a business case for this (Cloud), you're having to force fit a new world model into an old world model so you try to explain the new world model in old world terms and those things are not natural bedfellows. So even trying to - apples for apples- make financial comparisons can be difficult.

It took me a long time to actually get to grips with the change. You can intellectually understand it quite quickly but to sort of emotionally buy what you are being told and really begin to deeply understand how to might actually do that [implement a transition to Cloud provision] takes a bit more time.

The new world model seems to be governed by accommodation of variety, whereas in the traditional approach, reducing data and practices to fit with specific models was the norm. The latter is a process of reduction and in some instances simplification that would have little similarity to obtaining reality.

The cloud is an enabling technology. Cloud solutions, for example, allow DR to optimize some value added operations. For instance a successful national marketing campaign could be scaled up globally very rapidly or ERP systems could be deployed in ways that achieve further cost savings but the "commodified" nature of the cloud means that adoption of cloud solutions is unlikely to be allowed to encroach into areas of core expertise. DR's has distinctive capabilities in finding new oil and gas reserves, in geo-space analysis and in many other areas that are supported by high-performance computing environments. Strategically it is important that DR retains and develops its knowledge of crucial technologies. Cloud-based computing will allow DR to cut costs, be quicker to market and stay at the leading edge of support technologies so it is perceived to be an important tool that DR needs to deploy but not something that will allows DR to differentiate itself from competitors. In other words from DR's perspective the ability to deploy cloud computing solutions is a very important threshold capability but not a distinctive one. So competitive advantage acquired through greater internal efficiencies offered by cloud based services is going to be important for DR.

\section{FM: First move to the cloud}


Having made the decision, in principle, to move to a cloud-based solution for its web-sites, FM selected its provider through a traditional tendering process. It approached around five vendors who were known leaders in the web-hosting marketplace and put out a Request for Information (RFI). The RFIs paved the way for formal tenders that were evaluated using FM's usual internal protocols and scoring systems. The contract was awarded to a vendor who had the advantage of being located in the Thames Valley close to FM's own offices and the stand-by site was in London's Docklands.

FM's next major cloud venture accompanied its launch of its sporty, hybrid car, the BS-Y. The marketing team responsible for the launch was keen to utilize the power of social media and came up with the concept of Mode Art. Mode Art was described as a web-site and Facebook application which turned the user's life into art. User information was pulled from Facebook and then merged into a unique art composition based on one of the FM BS-Y's driving modes, namely Sport, Urban or Economy. The resulting artwork could be shared on Facebook, sent to friends or downloaded on to a mobile phone and was designed to act as a catalyst for viral marketing. The challenge for IT was to provide sufficient capacity for storing and processing users' images, particular given there was considerable uncertainty about possible uptake.

The ICT team supporting this launch decided to buy cloud-based storage capacity from Amazon, paying for it by gigabyte per month depending on utilization. This enabled the company to put storage capacity in place, in a matter of days and also had the advantage of allowing the company to specify where its data was to be stored, hence avoiding some of the legal issues concerning data protection that can be very complex when data is stored off-shore. Purchasing data storage from Amazon was, however, a commodity transaction and, at the time, Amazon was not geared to corporate customers as our respondent's experience vividly illustrated:

Amazon weren't geared to corporate buying. It actually ended up with me paying [for data storage] on my own corporate credit card. This was the only way we could do it because they weren't in a position to corporate purchase orders or to invoice the company.

Whilst FM as the purchaser had to accept Amazon's standard terms and conditions and had to navigate a payment system designed for individuals rather than corporates, the big benefit was in terms of price. 
As it turned out, the take-up for this campaign was much lower than expected but the low sunk costs meant that the failure of this particular marketing experiment contained as the following quote illustrates:

It does illustrate one of the great benefits of the Cloud in that this particular marketing campaign was not successful in terms of attracting people... But the great advantage was that I was paying something like 5 pence per month for the storage we got from Amazon whereas if we tried to provision it internally, we would have put, I don't know maybe a hundred gigs of storage or so behind it and we would have had to pay for it, provision it etc --- you would probably have been talking at least five to ten thousand pounds of infrastructure. ... The flexibility of Cloud storage and Cloud computing can give you some substantial cost advantages.

The above mentioned quote both the fact that prevalent low pricing advantages in the industry enabled FM to experiment without actually incurring substantial in-house costs, also this sort of ability to have resources maintained by the cloud provider meant that FM didn't have to monitor those resources. The latter provided FM an opportunity to concentrate on core-competencies rather than be drawn into allocating resources to maintain the storage. From the perspective of scalability, given that FM was going to have intermittent surges of activity there was need to have internet pipelines to garner cost advantages through cloud implementation. One of the subjects at FM had opined,

"We could have put in a much bigger pipe to the internet but that would have been a big pipe that was only used one percent of the time and was unlikely to be cost effective."

Whilst in FM's case its marketing teams had always been urged to take a creative approach to new product launches and were encouraged to take calculated risks, the changes in the cost structure associated with cloud-based web provision mitigated against downside risks and facilitated experimentation. Clearly such experimentation would have led to specificity and complexity (Mosakowski, 1997; Lippman and Rumelt, 1982) in the eventual resource that would add to properties of inimitability for FM.

The choice between private and public cloud solutions, required FM to engage with some difficult trade-offs. On the one hand, buying off-the-shelf public cloud services provided by firms like Amazon offered significant cost savings and flexible capacity but it also meant that FM still had to do a large amount of work in-house because they were "just buying the infrastructure rather than the solution." On the other hand the specialist providers like Rackspace offered high-end services and "get web-sites up and running quickly with little effort [on the buyer's part]" but highly customized solutions are expensive. In the end, FM went for a middle of the road solution that involved some degree of customization. 
The company that runs the IT helpdesk for FM (Europe) has its systems based in India. That involved getting data protection agreements signed with all the FM companies in Europe to say we approve employee data being held in systems in India. It's just a headache.

In terms of cost savings, the move to a quasi-public cloud was estimated by our respondent to

Result in a 30\% reduction in annual operating costs and ... to deliver a better solution. ... They call it the virtual team but if you look at the people that they [Phoenix] have supporting the web-site added to the people we had internally supporting the web-site there is definitely a higher level of support.

The issue of public, private or hybrid configurations obviously have cost ramifications as pointed out here. It seems to be evident here that a hybrid configuration like the one chosen is likely to fit with both affordability and capacity expectations.

One of the concerns commonly expressed about moves to cloud-based solutions is that there may be resistance to these kinds of developments from in-house IT staff, in part because the move to the cloud has the potential to reduce employment opportunities (Gupta et al., 2013). This does not appear to have been an issue at FM because there were more than enough new projects, continuously coming on stream to fully deploy the existing staff's time and expertise. In addition, many of the capabilities required did not exist in-house.

Computing is an area where there are always new technologies and new projects and you've got to decide where you are going to put your people. If you look at the skills required we have never had those in-house. Yes, we ran virtual servers in-house but running virtual servers between two sites that requires a level of $\mathrm{N}$-ware expertise that FM never really had in-house and would struggle to afford having in-house. We get 24/7 monitoring from the provider but if that was provisioned in-house we'd have to put our people on to shift systems which we can't do and we want the system to be scalable on demand so that the website automatically adds capacity if there are peaks in usage.

Skill and expertise are obviously central to new technology implementations. However, in this instance cloud tends to be heavily reliant of provider arrangements. Inflexibility in traditional staff deployment arrangements in FM are also an indicator of how control gets impacted by the need for scaling. Lin and Chen (2012) have argued that as dependence on service providers plummet over the longer term organisations gain specific competitive advantages. 
Respondents drew parallels between cloud computing technologies and outsourcing. In just the same way as a firm would be foolish to outsource activities that were the basis of its competitive advantage so a firm would be foolish to move computing activities to the Cloud if those activities formed part of the organisation's distinctive capabilities. To quote one respondent:

The only way Cloud computing helps in delivering competitive advantage is in a secondary way. Cloud computing can give you cost and speed market advantages so if part of your competitive advantage is getting to market quickly then Cloud computing can help. But, if you view computing in its own right as your competitive advantage then you don't outsource it because, by definition, you're using public things that people can easily copy, easily reproduce and so it very quickly doesn't become your competitive advantage anymore.

It is obvious from the abovementioned quote that expectation of outsourcing storage and social media applications are acceptable as long as core-competencies are entirely in the remit of the in-house capacities of FM. Looking to the future, however, it is likely that Cloud computing solutions will take on increasing significance for the car industry. There is a trend towards cars becoming network nodes in their own right - that is to say more information and communication technology being incorporated into vehicles so that cars are permanently online from the manufacturer's perspective. Whilst all car producers would like to gain an advantage by exploiting the opportunities that 'always online' cars potentially offer, it seems unlikely that a single car manufacturer could afford to invest the sums of money necessary to build unique systems and distinctive advantages.

We'd very much like to have a competitive advantage but, realistically, we probably can't because the cost of provisioning an 'always online' car and having the nationwide networks to do that is well outside the scope of a single car producer. We will probably have to collaborate with mobile network providers. We're going to be using other people to help us and we will need to tap into publicly available services so that is never going to be our competitive advantage. Our competitive advantage will have to be closer to home, for example by designing the interfaces, helping people to use the features of the car and so on.

The fact that Cloud solutions are ubiquitous and easily replicable (Wade and Hulland, 2004) means that careful consideration does need to be given to which activities are transferred to the Cloud. In the case of CRM and data mining, for example, our respondents were of the opinion that the interrogation of customer data is best done in-house.

[Interrogating customer data] and data mining is difficult is some ways. You are handling large volumes of data and, yes, that could be a candidate for the Cloud but then you look at the tools you need to handle those large volumes and to what extent are they Cloud-based? You can't shift large data over the network or the Internet. It needs to be closer to home. Lots of 
the data-mining people are now doing in-memory computing, holding databases in memory [to undertake their analysis]. If you're not careful you will erode your performance advantage by hosting remotely.

FM sees its core capabilities as located in its design of cars and in its manufacturing capabilities, so it needs its computing capacity next to the production line. Whilst cloud solutions and external hosting are helping the company to improve the efficiency and effectiveness of its overall operation, its production-related computing activities are likely to remain firmly in-house.

\section{Cross case analysis: Obtaining horizon}

An organization trying to implement cloud is expected to orient its development on certain parameters. As shown in table 1, we have highlighted the principal domains which were found to have identical footprints in both DR and FM respectively. Our case evidence suggests that dimensions such as industry expectations, process standardisation, scalability, investment optimisation/ Green credentials, and focus on core capacities as salient antecedents that may lead to value creation in practice.

\section{** Insert table 1 about here**}

The table also highlights the key obtaining variations among the two organisations that existed prior to the implementation of cloud within them. By virtue of the fact that DR was more inward facing, and in contrast FM needed regular customer interaction, cloud capacity that would lead the two companies to develop sustained competitive advantage in the market would also be somewhat different. Antecedents in table 1, does point to such specific variance among audiences.

\section{Discussion}

Revisiting the antecedents of cloud use among DR and FM, it is clear that the analyses have revealed the consequences of cloud integration from a unique resource perspective. Evidence gathered in both DR and FM point to the traditional technology neutral expectations at the start of the implementation. So for instance, managers had expected cloud integration would mainly enable the availability of greater storage. However, various dimensions which were to do with arrangements of cloud integration, including the intrinsic characteristics of cloud use meant that both organisations were led to indicate 
variations in their impacts. We delineate these along the lines of industry expectations, process standardisation, scalability, investment optimisation and green credentials, and focus on core capacities:

\section{Industry expectations}

There was impatience among the managers in both DR as well as FM to attempt a quick implementation of cloud computing, to acquire a head start to deploy functionality that would lead to going ahead of counterparts in the same industry. Such expectations are in agreement with unique trade advantages as envisaged through RBV within specific industries (Kraaijenbrink, et al., 2010; Peteraf, 1993). Variations in the way both DR and FM were structured, in comparison to the way cloud providers were prepared to integrate capacities (Mitra 2001) meant delays in implementations were normal. Managers in DR mentioned 'force fitting' capacity was tantamount to dismantling financial mechanisms of governance that were in place for more than two decades. Both acquiring new infrastructure as well as getting accustomed to the changed environment implied a degree of acceptability of the benefits of cloud based systems over traditional systems. In contrast, FM found that although cloud capacity did not lead them to greater engagement with new audiences in the markets yet they located significant internal cost advantages that enabled greater profitability that could be garnered over the long run. FM by passing over their storage onto the cloud that was looked after by Amazon, were paying a fraction of the costs that they would have had to pay to look after the data internally. Evidently, the freedom that was accorded to FM by the availability of unlimited cloud capacities would provide an unlimited space for customers to engage with prospective models of cars.

\section{Process standardisation}

Both DR and FM being multinational companies had developed their own ways of paying for resource use. In general, this would be based on a Capex model whereby a resource would be acquired in its entirety and then it would be used within the organisation. Often this would mean that much of the resource may remain unused. Whilst such waste through capital expenditure was common, it also meant that both DR and FM would develop their own customised ways of doing things. As cloud 
computing is entirely based on the Opex model cost is only calculated when a resource is used. So although this would mean a net benefit to the organisations involved by using only that amount of resource that is being used yet in reality this was conflictual to the way both organisations were accustomed to work. As was found in DR, this meant altering the decision making processes of the organisation. Literature on RBV suggests (cf. Barney, 1996; 2001; Priem and Butler, 2001; Wernerfelt, 1984) that alterations in the decision making process is potentially able to add to uniqueness and inimitability of organisational competencies.

\section{Lack of flexibility}

The lack flexibility on the part of the suppliers of cloud capacity like Amazon was another reality that the companies had not experienced before. Previous suppliers like HP had always bent backwards to accommodate customised support to these multinationals. They were now faced with a reality that would imply that they either accepted the packages that were made available by these providers or else miss the bus to keep up with industry expectations. Similar to ERP implementation in Nestlé (Mitra and Neale, 2014), cloud integration was more towards the garnering of internal efficiencies in the case of DR, its decision making structure was more affected in comparison to FM. It is likely, that as new internal efficiencies were acquired by DR, the eventual cost savings as well as change in the decision making infrastructure would have led to corporate growth for it. FM's cloud integration was more outward facing and so there were no drastic reshaping of organisational decision making practices at the outset.

\section{Scalability}

Respondents at DR seemed challenged by the reality of 'multi-tenant' environments of cloud services and the standard terms and conditions that were provided by Amazon. Evidently, this seems to have frustrated both DR and FM while purchasing cloud services as they had grown to be accustomed to be treated specially, and probably expected conciliatory trade negotiations unlike other smaller operators in their respective sectors. Both anytime, anywhere availability of cloud based systems as well 
as its unlimited space dimensions meant that it would enable both DR and FM to accommodate emergency surges in capacity requirements. Scalability (Yang and Tate 2012) being one of the most sought after capacity characteristics of cloud integration was found to impact both DR and FM in slightly different ways. While DR respondents found that solutions for their individual clients could be customised through the multi-tenant capacities of cloud systems yet they were unsure of the fact that such scalability may be affected by it's over reliance on a single supplier like Amazon. DR Managers were worried about the knock on effects on risk management brought about by inherent scalability of cloud based solutions. Essentially how does risk gets managed when the servers of Amazon were down or were inaccessible by the many clients of DR. Similar concerns were also expressed by the external engagement platforms being deployed by FM for developing customer generated content on cloud platforms. Where would the responsibilities of risk lie when the cloud platforms were inaccessible by customers? Clearly so long as vulnerabilities due to systems going down or being inaccessible remained, integration of cloud services within organisations will continue to have negligible effects on changes to the way decision making regarding risks will be dealt with by organisations. At the same time, it must be said that just like security that is being specially bolstered by cloud providers like Amazon and Microsoft (Runciman 2014), so too is greater resilience being continually pursued by providers such that downtimes are a thing of the past. If the latter were to be true then scalability would provide access to unlimited levels of flexible capacity that will inevitably contribute to corporate growth.

\section{Investment optimisation and green credentials}

While the Capex/Opex trade-offs as mentioned earlier would lead to optimisation of investment, increasingly green credentials are becoming important to be accepted parts of supply chain networks. Both the oil and natural gas environment of DR and the car manufacturing environment of FM today are domains where not only do organisations manufacture using 'green' means will have credibility among customers, suppliers-suppliers and customers-customers in supply chain networks today require these to sustain trading relations. In the case of DR by committing smaller amounts to upgrading of infrastructure development as cloud would require it would be feasible to be continually 
push up standards maintaining greener capacity. In the case of FM, procurement processes as well as cloud service providers would need to be continually compliant with obtaining international expectations. Greening of DR through cloud implementation would make decision making operationally robust as the long term is taken out of the equation. Cloud integration into DR would mean greater efficiencies to be found in internal processes. In the case of FM however, it is the external collaborators, for instance, organisations from where FM procures raw materials for manufacturing cars as well as the data centres where all their data would be held would need to comply with green expectations. So in the case of FM internal decision making could remain unaffected.

\section{Focus on core capacities}

Managers interviewed in both DR and FM reiterated that while they were initially distracted by the myriad characteristics of cloud integration, they soon realised that one of the greatest advantages would be that they could focus on their core competencies. DR has been well-known to have capacities in finding oil and gas reserves, carry out geo-space analysis using high-performance computing. Also strategically DR needs to sustain its knowledge competencies in crucial technologies. So here if most of the storage and access to high performance computing is aided by cloud based systems then DR has every chance to focus on their core competencies. It is likely that alterations to information management infrastructures as a result of cloud capacities is going to lead corporate growth for DR as they succeed in maintaining high standards in using their core-competencies. Over time such a focus on core-competencies could lead to emergent IT capacity that are both inimitable and distinctive for DR (Ravichandran and Lertwongsatien, 2005). In the case of FM, it is clear that there is a skill shortage in maintaining internal computing infrastructures. Respondents at FM indicated skill shortage challenges with regard to NWare expertise when they ran virtual servers between a couple of sites. Therefore, with cloud capacities as they would be looked after by providers, FM can concentrate on their core-capacities of car manufacturing. From such a perspective integration of cloud capacity into FM's infrastructure is going to make managerial decision making competent as it would be focused on core capacities of the car manufacturing sector. As there will be a reduction in the need for in-house 
management of the information infrastructure, it is likely that greater focus on core competencies would lead to corporate growth.

In the case of DR it is clear that there have been far reaching alterations in decision making practices by introduction of cloud computing. Managers in DR have reported that whole process changes have impacted on issues relating to legal frameworks, billing, charging for IT services and the way performance is measured. Admittedly, competitive advantages have accrued through internal cost savings as a result of cloud implementation. Such implementation wasn't easy as there were conflicts between age old practices of DR and what was admissible within the new intrinsic infrastructure of cloud based services. In the case of FM, decision making alterations were most noticeable in the marketing division of the organisation. Here a network effect with potential customers, contributed to the flexibility with which designs could be vetted through future audience expectations. The information systems infrastructure of DR was significantly enabled by cloud integration within it. Cost savings and efficiency gains brought about by cloud implementation would have significantly enhanced the competitive advantage of a large corporation like DR.

Our data evidence suggests that the emergence of a direct relationship between information systems infrastructure and the ability to garner sustained competitive advantage through corporate growth. Success of FM would be increasingly based on the level of participation of prospective customers in social media platforms on new car models. Additionally as the company would be supporting cars through a cloud based networked environment, it is likely that it would be feasible to continuously engage with the public. Our study shows that the balance of power between purchasers and providers of cloud solutions seems to be different to those that have traditionally been widely known. Both DR and FM reported that they were not treated in any special way by proprietary cloud providers as large multinationals like them have been accustomed to be. This is interesting, as the mind set of commodified service might have influenced the providers of cloud services in similar ways as the users of it are likely to be. Commodification seems to be able to generate a sort of mutual exclusivity between ownership of a resource and its conditions of sale in hitherto unknown ways. In some ways this sort 
of a distance between the dual capacities of a provider is probably able to make markets and resources more competitively attractive to users of those capacities.

Being in the sectors that DR and FM are located in, expectations of access to data and their processing are different. DR being in the oil and natural gas sector seems to have virtually no need for feedback or widespread interaction from and with customers who use fuels that DR produces. At the same time DR has more than eight hundred and thirty thousand employees worldwide who need to be able to interact through email. Further, asset management can be a major requirement of the oil and natural gas sector. Here reliable information management can play a key role in the successful implementation to a cloud based solution. As reiterated by Perrons and Hems (2013), reliance of public clouds is likely to become inevitable, as security infrastructure becomes reliable across the cloud industry. The experience within DR shows that this transition into a cloud infrastructure is gradually influencing decision making, mind sets within the organisation are changing. It may be argued that styles of decision making (Mitra 2001) as traditionally practised within DR are being impacted upon by transition into a cloud infrastructure. Following Runciman (2014) it is unlikely that it would be feasible to seamlessly migrate all legacy data onto cloud based repositories for going concerns like DR and FM.

Our DR respondents reiterated the change in financial models that would have to be introduced with SaaS that would impact on the way the organisation had been accustomed to work. This was more of a paradigm shift from the way the organisation had hitherto planned, created and distributed its resources.

In contrast to DR, FM's business horizon is quite clearly identified by the need to interact with audiences that include both current and prospective customers of its cars. In a world where successful organisations enable customers to participate in the design process and thus contribute to the value creation process, it is obvious that surplus capacity for such activities might be better created by provisioning of hybrid clouds. Oliveira et al (2014) support this idea when they examine the manufacturing sector's service needs through cloud based capacity building among European organisations. Data collection within FM revealed that social media like Face Book has been extensively used to measure customer preferences and projections that would enable launch of new models among 
its ranges. Admittedly, this sort of interaction produces vast amounts of data that can hardly be accommodated within existing organisational repositories. Social media led viral marketing is always going to be at the forefront of FM's strategy that would be reliant on unlimited capacities afforded by the cloud.

Emphasis of cloud development for FM was also similar to outsourcing initiatives in organisations. Given their lack of manpower resources, it also seemed logical to use outsourcing as that way they could save employing additional staff or in-house training costs.

Cost and speed advantages were specific dimensions that both DR and FM's respondents felt got added through their cloud use. Although FM seems to be sceptical about the security implications of holding big data onto cloud networks yet practitioner sources confirm proprietary cloud providers like Amazon and Microsoft have been steadily improving their security infrastructure in keeping with rising industry expectations. It is interesting to note that both DR and FM have reiterated that they don't consider uniqueness to be necessarily a feature of their cloud based capacities. While this may be a view from inside these organisations it is obvious that the knowledge based as well as flexible capabilities (Kraaijenbrink et al. 2010) that would be generated are going to produce unique advantages that competitors will find hard to challenge.

\section{Conclusion:}

After examining both cases of DR and FM's experiences of cloud implementation it is clear that corporate growth has taken different formats for the two organizations. This may have been also attributed to some extent to the difference in the type of industries in which the two organizations are located in. However, the challenges both organizations encountered in aligning cloud use with current organizational practices reveal how a technical infrastructural component like the cloud can bring about profound alterations to taken for granted paradigms that have sustained organizations up to this point. Our study reiterates the capacities of swiftness to scale up organizational performance, flexibility in developing cost effective solutions, propensity to use opex approaches to engender green credentials, and ability to direct resources to develop and deliver core competencies to be the principal ways in 
which corporate growth is facilitated by cloud implementation. Obviously cloud deployment enables fostering of green credentials as provider organizations have to increasingly demonstrate that they are incorporating sophisticated, eco-friendly features into the design and operation of their data centres.

\section{Lessons for practice}

Specifically the key resource required for generating value from the cloud is the skill of combining external partners' requirements and inputs to developing new unique solutions. In this regard, integration of cloud within a large organisation like Deepwater's Rigs could lead to alteration of decision making infrastructures, which in turn, helps to improve the variability, intensity, and volume of information available for decision making. For organisations like Fuji Motors, that are reliant on popularity of products among audiences, an upshot is the instantaneous engagement with customers, suppliers, and other groups embedded within the firm's value network.

While we acknowledge that changing technological trajectories of cloud computing makes it difficult to develop managerial formulae or recipes, our research holds some implications for the adoption and deployment of cloud computing in contemporary organising. First, managers need to be aware of the contextual resource influences of cloud implementation. For organisations like DR where public interaction is not important, cloud is likely to play a role in the reshaping of organisational information flows. Access to volume of information is a key resource that affected by cloud implementation within DR. In contrast, managers in FM would need to deal more extensively with customer engagement as they manufacture products, that to be successful, will require considerable compatibility with customer expectations. Invariably customer engagement means characteristics of variability and velocity (McCreary and Kelly, 2013) would be key drivers of resource value among FM type organisations. Today's customer engagement is replete with interactions on myriad social media platforms where all kinds of trends in appreciation can be discerned. The speed with which FM managers would react to such customer opinions would account for the velocity dimensions. Second, managers need to be aware of the movement towards core capacities that cloud implementation tends to encourage. By 
automating access and use of various resources for customers, management can concentrate on their core capabilities. Resources freed up by cloud implementations will lead to re-deployment of these resources such that core competencies will become specific focus on uniqueness. Industry related skills directed towards core-competencies are likely to create unique and sustainable differentiators that over time could become abiding.

\section{Implications for theory builders}

The resource based view argues that resources including assets, capabilities, and processes may lead to competitive advantage when they are valuable, rare, inimitable and organized. Mobile and heterogeneously distributed across firms, the strategic configuration of these resources may lead to sustained competitiveness. In this paper, we argue that while cloud implementation ability is valuable (V), it is not necessarily rare (R) or Inimitable (I). There exists a strong market for individuals and organizations with skills in cloud deployment. In this regard, the resource (competencies in cloud computing), is essentially tradable (Kraaijenbrink, et al., 2010; Peteraf, 1993). Nevertheless, we found that the skills required for successful implementation of the cloud tend to possess mobility barriers. The tacitness of these skills, we observe, make the source of competitiveness derived from cloud computing difficult to unpack by competitors (Mosakowski, 1997). In the IS context, the development of such skills serve to impede imitation and becomes a critical resource underpinning competitiveness. However, as has been pointed out earlier in this study that the tension between conceptualisations of causal ambiguity that is dependent on tacitness, complexity and specificity on the one hand and the value, rarity or inimitability of resources on the other continues to be an abiding driver of subjectivity for RBV to be a theoretical lens. Over time as cloud will become more widely integrated into organisations, unique resource development based on the skills of the staff and deployment characteristics of the context are likely to determine ensuing competitive advantages for cloud using organisations. Theory builders need to figure out a mechanism by which the subjective nature of causal ambiguity of unique resources reliant on tacitness, complexity and specificity in contrast to value, rarity and inimitability of cloud using organisations could be measured more objectively. 
Despite the present study, offering several insights into the creation and capture of value from cloud based computing. Our findings delineate a snapshot of manager experiences who were themselves involved in choosing cloud platforms whereas these could have been further enriched by more detailed analysis of grass root worker conceptualisations of skill use within installations of the focal organisations in different parts of the world. Given the particularities of the organisations that were involved in this study, their distinct information orientations and relational positions within their organizational hierarchies, care should be taken in generalizing the resource influences we observed across the two organisations. Similar studies with respect to other firms, in industrial sectors that need applications of skill among users, may be necessary to ascertain whether additional insights and findings can be observed or generated. We encourage such studies to strive also to account for the level of inimitability of resource uses, as a result of the absorption of knowledge and skills which may potentially have an influence on their propensity to engage in garnering unique advantages within industries.

\section{References:}

Armbrust, M., Fox, A., Griffith, R., Joseph, A.D., Katz, R., Konwinski, A., Lee, G., Patterson, D., Rabkin, A., Stoica, I., and Zaharia, M. (2010). 'A view of cloud computing,' Communications of the ACM, 53(4), 50-58

Avram, M.G. (2014). 'Advantages and challenges of adopting cloud computing from an enterprise perspective,' Procedia Technology, 12, 529-534

Ba, S., Stalleart, J., and Whinston, A.B. (2001). 'Research commentary: Introducing a third dimension in information systems design - The case for incentive alignment,' Information Systems Research, 12(3), 225-239.

Bargar, R. R., and Duncan, J. K. (1982). Cultivating creative endeavor in doctoral research. The Journal of Higher Education, 53(1), 1-31.

Barney, J. B. (1996). The resource-based theory of the firm. Organization Science, 7(5), 469-469.

Barney, J. B. (2001). Is the resource-based "view" a useful perspective for strategic management research? Yes. Academy of Management Review, 26(1), 41-56.

Bharadwaj, A.S. (2000). 'A resource based perspective on information technology capability and firm performance: an empirical investigation,’ MIS Quarterly, 24(1), 169-196 
Chan, Y.E., and Reich, B.H. (2007). 'IT alignment: What have we learned?' Journal of Information Technology, 22(4), 297-315

Choudhary, V., and Vithayathil, J. (2013). 'The impact of cloud computing: Should the IT department be organised as a cost center or a profit center?' Journal of Management Information Systems, 30(2), 67-100

Christensen, C. M., and Overdorf, M. (2000). 'Meeting the challenge of disruptive change,' Harvard Business Review, 78(2), 66-77

Mendonça, S., e Cunha, M. P., Kaivo-oja, J., \& Ruff, F. (2004). Wild cards, weak signals and organisational improvisation. Futures, 36(2), 201-218.

Day, G.S. (1994). 'The capabilities of market driven organisations,' Journal of Marketing, 58(4), 37-52

Dillon, T., Wu, C., and Chang, E. (2010). 'Cloud computing: Issues and challenges,' Proceedings of the 24th International Conference on Advanced Information Networking and Applications, IEEE Computer Society

Drnevich, P.L., and Croson, D.C. (2013). 'Information technology and business level strategy: Toward an integrated theoretical perspective,' MISQuarterly, 37(2), 483-509

Dubé, L., and Paré, G. (2003). 'Rigor in Information Systems Positivist Case Research: Current Practices, Trends, and Recommendations,' MIS Quarterly, 27(4), 597-636

Ebbers, M., O’Brien, W., and Ogden, B. (2006). Introduction to the new mainframe: z/OS Basics, IBM Redbooks

Galbreath, J. (2005). 'Which resources matter the most to firm success? An exploratory study of resource based theory,' Technovation, 25(9), 979-987

Grant, R.M. (1996a). 'Prospering in dynamically competitive environments: Organizational capability as knowledge integration,' Organisation Science, 7: 375-387

Grant, R.M. (1996b). 'Toward a knowledge-based theory of the firm,' Strategic Management Journal, 17: 109-122

Grossman, R.L. (2009). 'The case for cloud computing,' IEEE Computer Society, 23-27

Gupta, P., Seetharaman, A., and Raj, J.R. (2013). 'The usage and adoption of cloud computing by small and medium businesses,' International Journal of Information Management, 33(5), 861-874

Hirschheim, R., and Sabherwal, R. (2001). 'Detours in the path toward strategic information systems alignment,' California Management Review, 44(1), 87-108

Hsu, P-F, Ray, S., and Li-Hsieh, Y-Y. (2014). 'Examining cloud computing adoption intention, pricing mechanism, and deployment model,' International Journal of Information Management, 34(4), 474-488

Khanagha, S., Volberda, H., Sidhu, J., and Oshri, I. (2013). 'Management innovation and adoption of emerging technologies: The case of cloud computing,' European Management Review, 10(1), 51-67.

King, A. W., \& Zeithaml, C. P. (2001). Competencies and firm performance: Examining the causal ambiguity paradox. Strategic Management Journal, 75-99. 
Kraaijenbrink, J., Spender, J-C., and Groen, A.J. (2010). 'The resource based view: A review and assessment of its critiques,' Journal of Management, 36(1), 349-372

Lederer, A.L., and Mendelow, A.L. (1989). 'Co-ordination of information systems plans with business plans,' Journal of Management Information Systems, 6(2), 5-19

Leonard-Barton, D. (1992). 'Core capabilities and core rigidities: A paradox in managing new product development,' Strategic Management Journal, 13: 111-125

Lippman, S. A., \& Rumelt, R. P. (1982). Uncertain imitability: An analysis of interfirm differences in efficiency under competition. The Bell Journal of Economics, 418-438.

Loveridge, D. (2009). Foresight: The Art and Science of Anticipating the Future, Routledge.

Luftman, J. (2003). ‘Assessing IT/Business alignment,' Information Systems Management, 20(4), 9-15

Marston, S., Li, Z., Bandopadhyay, S., Zhang, J., and Ghalsasi, A. (2011). 'Cloud computing - The business perspective,' Decision Support Systems, 51, 176-189

Martens, B., and Teuteberg, F. (2012). 'Decision making in cloud computing environments: A cost and risk based approach,' Information System Frontiers, 14(4), 871-893

McCreary, D., and Kelly, A. (2013). Making sense of NoSQL, Manning

Mell, P., and Grance, T. (2011). The NIST definition of cloud computing.

Mosakowski, E. (1997). Strategy making under causal ambiguity: Conceptual issues and empirical evidence. Organization Science, 8(4), 414-442.

Mitra, A. (2001). 'An Interpretation of the Organisational Context of Geographic Information System use in British Local Government,' Unpublished PhD dissertation, University of Birmingham

Mitra, A., and Neale, P. (2014). 'Visions of a pole position: Developing inimitable resource capacity through enterprise systems implementation in Nestlé,'Strategic Change, 23(3-4), 225-235

Oliveira, T., Thomas, M., and Espadanal, M. (2014). 'Assessing the determinants of cloud computing adoption: An analysis of the manufacturing and services sectors,' Information \& Management, 51(5), $497-$ 510

Perrons, R. K., and Hems, A. (2013). 'Cloud computing in the upstream oil and gas industry: A proposed way forward,' Energy Policy, 56, $732-737$

Pollalis, Y.A. (2003). 'Patterns of co-alignment in information intensive organisations: business performance through integration strategies,' International Journal of Information Management, 23(6), 469492.

Priem, R. L., \& Butler, J. E. (2001). Is the resource-based "view" a useful perspective for strategic management research?. Academy of management review, 26(1), 22-40.

Priem, Richard L., and John E. Butler. (2001b) "Tautology in the resource-based view and the implications of externally determined resource value: Further comments." Academy of Management review 26.1 (2001): 57-66. 
Ragin, C.C. (1994). Constructing Social Research. Thousand Oaks, CA.

Ravichandran, T., and Lertwongsatien, C. (2005). 'Effect of information systems resources and capabilities on firm performance: a resource based perspective,' Journal of Management Information Systems, 21(4), 237-276.

Ritchie, J., and Spencer, L. (1993). Analyæing Qualitative Data, Routledge.

Roland, G. (2004). Understanding institutional change: Fast-moving and slow-moving institutions. Studies in Comparative International Development (SCID), 38(4), 109-131.

Runciman, B. (2014). 'The IT Linguist', ITNOW, Journal of the British Computer Society, June 56-57

Sarkar, P., and Young, L. (2011). 'Sailing the cloud: A case study of perceptions and changing roles in an Australian University,' Proceedings of the European Conference on Information Systems, Paper 124, Aalto University, Helsinki, Finland

Strauss, A. (1978). A social world perspective. Studies in symbolic interaction, 1(1), 119-128.

Sultan, N. (2014). 'Servitization of the IT Industry: The cloud phenomenon,' Strategic Change, 23(5-6), 375-388

Tallon, P.P. (2007). 'A process-oriented perspective on the alignment of information technology and business strategy,' Journal of Management Information Systems, 24(3), 227-268.

Voorsluys, W., Broberg, J., \& Buyya, R. (2011). Introduction to cloud computing. Cloud computing: Principles and paradigms, 1-41.

Wade, M., and Hulland, J. (2004). 'The resource based view and IS research: Review, extension, and suggestions for future research,' MIS Quarterly, 28(1), 107-142

Walsham, G. (1995). 'Interpretive case studies in IS research: nature and method,' European Journal of Information Systems, 4(2), 74-81

Waschke, M. (2012). Cloud Standards: Agreements that hold together clouds, CA technologies.

Wernerfelt, B. (1984). A resource-based view of the firm. Strategic Management Journal, 5(2), 171-180.

Wiengarten, F., Humphreys, P., Cao, G., and McHugh, M. (2012). 'Exploring the important role of organisational factors in IT business value: Taking a contingency perspective on the resource based view,' International Journal of Management Reviews, 15(1), 30-46

Yang, H., and Tate, M. (2012). 'A descriptive literature review and classification of cloud computing research,' Communications of the Association for Information Systems, 31(1), 35-60

Yin, R. K. (2013). Case study research: Design and methods. Sage publications. 